\title{
Beneficial effects of biochar application on lettuce (Lactuca sativa L.) growth, root morphological traits and physiological properties
}

\author{
Dilfuza Jabborova *,**, Dilbar Kadirova***, Abdujalil Narimanov* and Stephan Wirth** \\ *Institute of Genetics and Plant Experimental Biology, 111208 Kibray, Uzbekistan \\ **Leibniz Centre for Agricultural Landscape Research (ZALF), 15374 Müncheberg, Germany \\ ***Termez State University, 190111, Termez, Uzbekistan
}

\section{Article Info}

Article history

Revised 19 October 2021

Accepted 21 October 2021

Published Online 30 December 2021

\section{Keywords}

Lettuce

Biochar

Plant growth

Chlorophyll content

Soil enzymes
Received 1 September 2021

\begin{abstract}
Biochar application is widely used to improve plant growth by increasing soil fertility. This study aimed to assess the effect of biochar on lettuce growth, root morphological traits and physiological properties under greenhouse conditions. The study was performed in a greenhouse, using biochar additions of $1 \%, 2 \%$ and $3 \%$ in a pot experiment. The plant parameters assessed under greenhouse conditions were the germination rate, leaf length, leaf number, leaf width as well as fresh root weight, fresh shoot weight, dry root weight, dry shoot weight, and root morphological traits. Furthermore, chlorophyll content and relative water content were evaluated. Both biochar $2 \%$ and biochar $3 \%$ treatment ssignificantly improved lettuce growth (leaf length, leaf number, leaf width) compared with the control, while no significant differences were observed in the biochar $1 \%$ treatment. However, biochar $3 \%$ treatment significantly enhanced the root morphological traits such as total root length, the root surface area, the projected area and the root volume compared to the control. The total chlorophyll content and carotenoid content improved with increasing levels of biochar 3\% treatment, which significantly increased by $43 \%$ and $51 \%$ compared with the control. The highest acid phosphomonoestrase activities were seen with the application of biochar $3 \%$, which was $19 \%$ and $31 \%$ higher than that of the biochar $1 \%$ and control treatments, respectively. Moreover, a significant increase in soil enzyme activities (fluorescein diacetate hydrolase, acid and alkaline phosphomonoestrase) was observed with the biochar $2 \%$ and biochar $3 \%$ treatments compared to the control. This study indicated that biochar could promote lettuce growth and enhance soil enzyme activities.
\end{abstract}

\section{Introduction}

Lettuce (Lactuca sativa L.) is an annual plant of the aster family, Asteraceae and one of the most important leafy vegetable mainly used for fresh consumption or commonly served as salad applications (Labeda et al., 2007; Chiesa et al., 2009). This vegetable has several health benefits attributed to the presence of high levels of phytonutrients, high contents of vitamins $\mathrm{K}$ and $\mathrm{A}$, beta-carotene as well as fiber content, phenolic compounds, and minerals such as calcium, phosphorus, potassium, manganese and iron (Mulabagal et al., 2010; Mulabagal et al., 2010; Jaiswal, 2020; Xylia et al., 2021). For successful cultivation, lettuce requires ample water and nutrient supply, especially in warmer conditions.

Biochar is a coal-like material obtained by pyrolysis of biomass which is used as soil improvement in agriculture (Kookana et al., 2011; Adrados et al., 2015). Many reports have shown that biochar application improved microbial activity, soil physical and chemical properties (Asai et al., 2009; Lehmann et al., 2011; Hale et al., 2013; Martinsen et al., 2015). Recently, Laird et al. (2010) reported that the biochar application enhanced the specific surface area, water

\section{Corresponding author: Dr. Dilfuza Jabborova}

Associate Professor, Institute of Genetics and Plant Experimental Biology, Kibray-111208, Uzbekistan

E-mail: dilfuzajabborova@yahoo.com

Tel.: +91-8595092177

Copyright () 2021 Ukaaz Publications. All rights reserved.

Email: ukaaz@yahoo.com; Website: www.ukaazpublications.com holding capacity and cation exchange capacity. Scisowsk et al., (2015) showed that the application of biochar had a positive effect on soil quality and productivity. Jabborova et al. (2020) demonstrated that biochar improved contents of soil nutrients such as total nitrogen, potassium and phosphorus. Furthermore, several researchers reported that biochar improved soil enzyme activities such as dehydrogenase, alkaline and acid phosphatase, acid and alkaline phosphomonoesterase, proteases, lipase-esterase, and esterase (Anderson et al., 2011; Jabborova et al., 2021a; Jabborova et al., 2021b; Jabborova et al., 2021c). Soil catalase activity, phosphatase activity and urease activity were higher in the treatment with the highest application rate of biochar treatment (Oladele et al., 2019).

Biochar application can play an important role in different crops growth, yield, plant nutrients and plant physiological properties (Jabborova et al., 2020; Hashem et al.. 2019; Jabborova et al., 2021d). Vaccari et al. (2015) demonstrated that biochar treatments could enhance vegetative plant growth such as plant height, stem diameter, root dry weight and root length in tomatoes. Vaughn et al. (2020) found that $5 \%$ organic biochar and $10 \%$ organic biochar had increased seed germination and fresh weights per plant of tomato plants. Tomoto leaf samples concentrations of nitrogen $(\mathrm{N})$, potassium $(\mathrm{K})$, magnesium $(\mathrm{Mg})$ and phosphorus $(\mathrm{P})$ were also significantly higher in biochar treatments (Vaccari et al., 2015). The application of biochar significantly enhanced cabbage seedling production as reported by Chrysargyris et al. (2019). Numerous studies have revealed that 
biochar application improved plant photosynthesis, chlorophyll content, transpiration rate and relative water content (Speratti et al., 2018; Jabborova et al., 2021b; Jabborova et al., 2021d; Yoo et al., 2021). Thus, the relative water content, yield, and quality of tomatoes significantly increased by biochar application (Akhtar et al., 2014). The biochar amendment significantly increased the photosynthetic rate in okra (Abelmoschus esculentus L.) as reported by Sarma et al. (2017). Individual applications of biochar significant increase in leaf numbers and leaf areas in faba bean (Vicia faba L.), reported by Nahhas et al. (2021). Biochar treatments increased the chlorophyll $\mathrm{a}$, chlorophyll $\mathrm{b}$, and total photosynthetic pigments in chickpea (Hashem et al., 2019). Accordingly, the contents of chlorophyll a and $\mathrm{b}$ as well as total chlorophyll content of lettuce significantly increased at a biochar application of 7.5\% (Chrysargyris et al. 2020).

However, detailed information on the effects of biochar on the morphological and physiological characteristics of lettuce leaves and roots is still lacking. The objectives of this study were thus to reveal the impacts of biochar application on lettuce growth and plant physiological properties, as well as on root morphological traits and soil enzyme activities in more detail.

\section{Materials and Methods}

\subsection{Surface sterilization and germination of seeds}

Lettuce seeds were sorted to eliminate broken, tiny, or infected seeds and sterilized with $10 \%$ sodium hypochlorite solution for three minutes and washed three times with sterile, distilled water. Lettuce seeds were germinated in $85 \mathrm{~mm} \times 15 \mathrm{~mm}$ tight-fitting plastic Petri dishes with $5 \mathrm{ml}$ of water. The dishes were placed in incubator at temperature $28-30^{\circ} \mathrm{C}$.

\subsection{Experimental design}

The impact of biochar levels on the growth of lettuce was investigated in a greenhouse at ZALF, Müncheberg, Germany.The treatments included control (soil without biochar) and soil with three levels of biochar $(1 \%, 2 \%$ and $3 \%)$. The lettuce was grown for 35 days at 24 ${ }^{\circ} \mathrm{C}$ day and $16^{\circ} \mathrm{C}$ at night. The experiments were carried out in a randomized block design with five replications. Seed were sown into plastic pots, including $400 \mathrm{~g}$ of soil. All pots were watered every three days. The germination rate, leaf length, leaf number and width, fresh root and fresh shoot weight, dry root and dry shoot weight were measured after 35 days.

\subsection{Measurement of root morphological traits}

The lettuce roots were washed thoroughly and the entire root system was spread out and analyzed using a scanning system (Expression 4990, Epson, CA).The digital images of the root system were finally analyzed using the Win RHIZO software (Régent Instruments, Québec, Canada). Thus, the total root length, the root surface area, the root volume, the projected area and the root diameter were analyzed.

\subsection{Measurement of physiological parameters}

Total chlorophyll content and carotenoid contents were analyzed by the modified method of Hiscox and Israelstam (1979). Fifty mg fine pieces of 2 to $3 \mathrm{~mm}$ size fresh leaf sample were cut and added to test tubes containing $5 \mathrm{ml}$ DMSO. Then the test tubes were incubated at $37^{\circ} \mathrm{C}$ for $4 \mathrm{~h}$ in the dark. The incubation was continued until a completely colorless tissue was obtained. The absorbance of the extract was taken at $470 \mathrm{~nm}, 645 \mathrm{~nm}$ and $663 \mathrm{~nm}$ using a spectrophotometer against DMSO blank.

The relative water content was determined by the method of Barrs and Weatherly (1962). One hundred mg fully expanded fresh leaf sample (FW) was placed immediately after sampling in Petri plates filled with double distilled water for $4 \mathrm{~h}$ at room temperature. The samples were then taken out, blotted, dried and the turgid weight (TW) was recorded. Then, the samples were kept in an oven at $70^{\circ} \mathrm{C}$ overnight, and finally dry weight was recorded (DR). The relative water content was calculated as: RWC $(\%)=[(\mathrm{FW}-\mathrm{DW}) /$ (TW-DW)] X 100.

\subsection{Determniation of soil enzyme activities}

Soil enzymes such as the acid and alkaline phosphatase activities were evaluated by the method of Tabatabai and Bremner (1969).The fluorescein diacetat hydrolytic activity was analyzed by the method of Green et al. (2006). In brief, a total of $0.5 \mathrm{mg}$ soil was added to 25 $\mathrm{ml}$ of sodium phosphate (0.06 M; pH 7.6). $0.25 \mathrm{ml}$ of $4.9 \mu \mathrm{M}$ fluorescein diacetate substrate solution was added to all assay vials. Each vial was mixed and incubated in a water bath at $37^{\circ} \mathrm{C}$ for $2 \mathrm{~h}$. The soil suspension was centrifuged at $8000 \mathrm{rpm}$ for $5 \mathrm{~min}$. The clear supernatant was measured at $490 \mathrm{~nm}$ against a blank reagent solution in a spectrophotometer (Spectra Max Plus 384).

The phenoloxidase (POX) activity was determined following the method of Floch et al. (2007). A modified universal buffer (MUB) stock solution was prepared according to Tabatabai (1994) by dissolving $12.1 \mathrm{~g}$ of tris (hydroxymethyl) aminomethane (THAM), $11.6 \mathrm{~g}$ of maleic acid, $14.0 \mathrm{~g}$ of citric acid, and $6.3 \mathrm{~g}$ of boric acid $\left(\mathrm{H}_{3} \mathrm{BO}_{3}\right)$ in $488 \mathrm{ml}$ of a $1 \mathrm{M}$ sodium hydroxide $(\mathrm{NaOH})$ and diluting the solution to 1 litre with bidistilled water. Then, $200 \mathrm{ml}$ of the MUB stock solution was titrated to the desired $\mathrm{pH}$ by using $0.1 \mathrm{M}$ hydrochloric acid $(\mathrm{HCl})$ or $0.1 \mathrm{MNaOH}$, and the volume was adjusted to 1 liter with bidistilled water. An ABTS (2,22 - azinobis-(3ethylbenzothiazoline-6-sulfononic acid) diammonium salt stock solution was made by dissolving $0.548 \mathrm{~g}$ ABTS in $10 \mathrm{ml}$ of bidistilled water for a final concentration of $0.1 \mathrm{M}$ ABTS. POX activity was measured by spectrophotometer (Spectra Max Plus 384) using ABTS as the substrate. The reaction mixture contained: $1.0 \mathrm{~g}$ of soil, $10 \mathrm{ml}$ of MUB solution $\mathrm{pH} 4.0$ and $200 \mu \mathrm{l}$ of a $0.1 \mathrm{M}$ ABTS solution. The ABTS concentration in the incubation mixture was $2 \mathrm{mM}$. After incubation at $30^{\circ} \mathrm{C}$ for $5 \mathrm{~min}$, the mixture was centrifuged at 12000 $\mathrm{rpm}$ at $4^{\circ} \mathrm{C}$ for $2 \mathrm{~min}$, and the supernatant was measured at $420 \mathrm{~nm}$.

\subsection{Statistical analyses}

Experimental data were analyzed with the Stat View Software using one-way ANOVA. The significance of the treatment effect was determined by the magnitude of the $\mathrm{F}$ value $(p<0.05,<0.001)$.

\section{Results}

\subsection{Germination of seed}

The biochar application levels of 1\%, 2\% and 3\% biochar improved seed germination. Both biochar amendment of $1 \%$ and $2 \%$ enhanced the seed germination after three and four days compared to the control. Biochar amendment of 3\% increased the seed germination by $100 \%$ compared to the control on days three and four (Figure 1). 


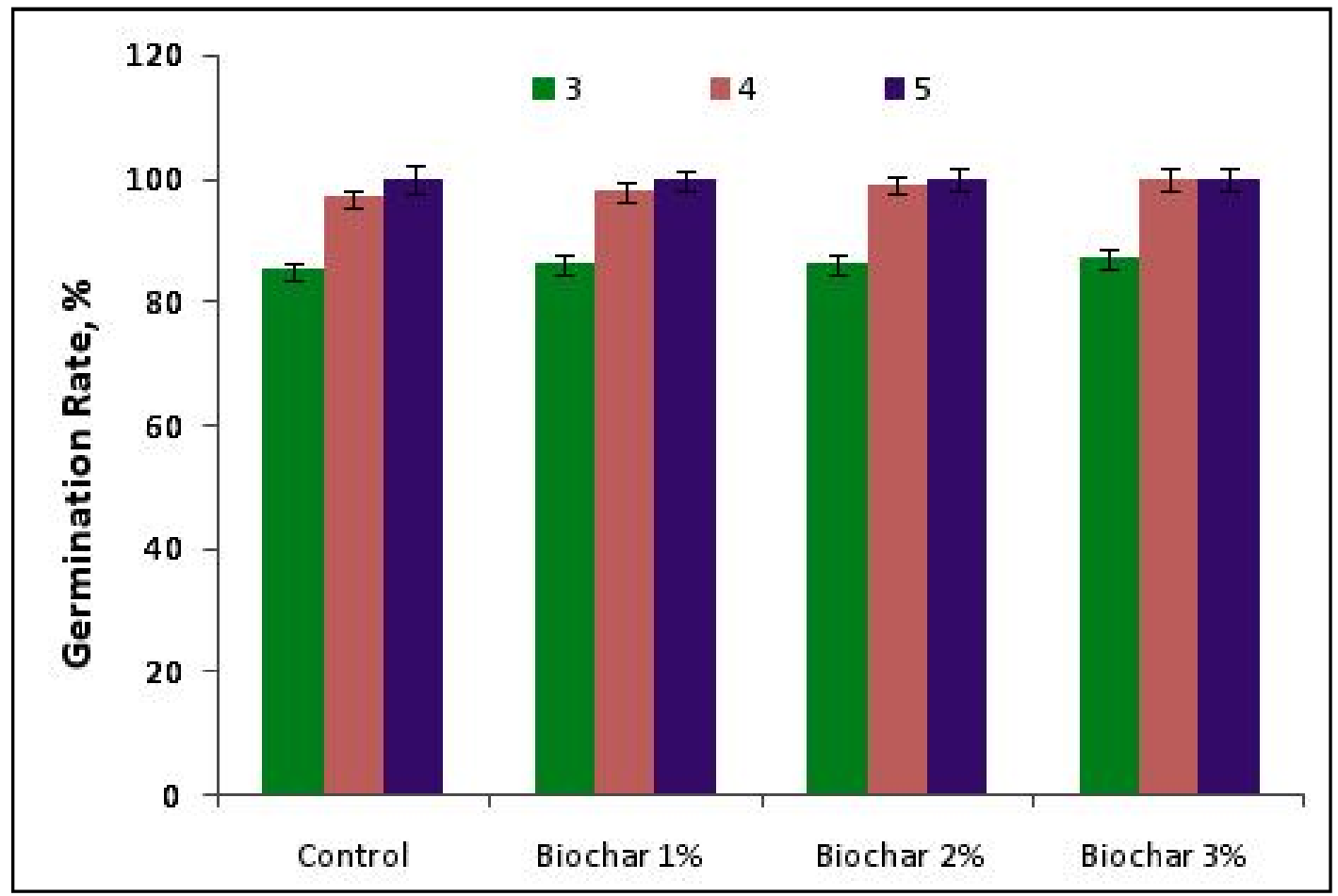

Figure 1: Effects of biochar amendments $(1 \%, 2 \%, 3 \%)$ on the germination rate of lettuce after 3-5 days.

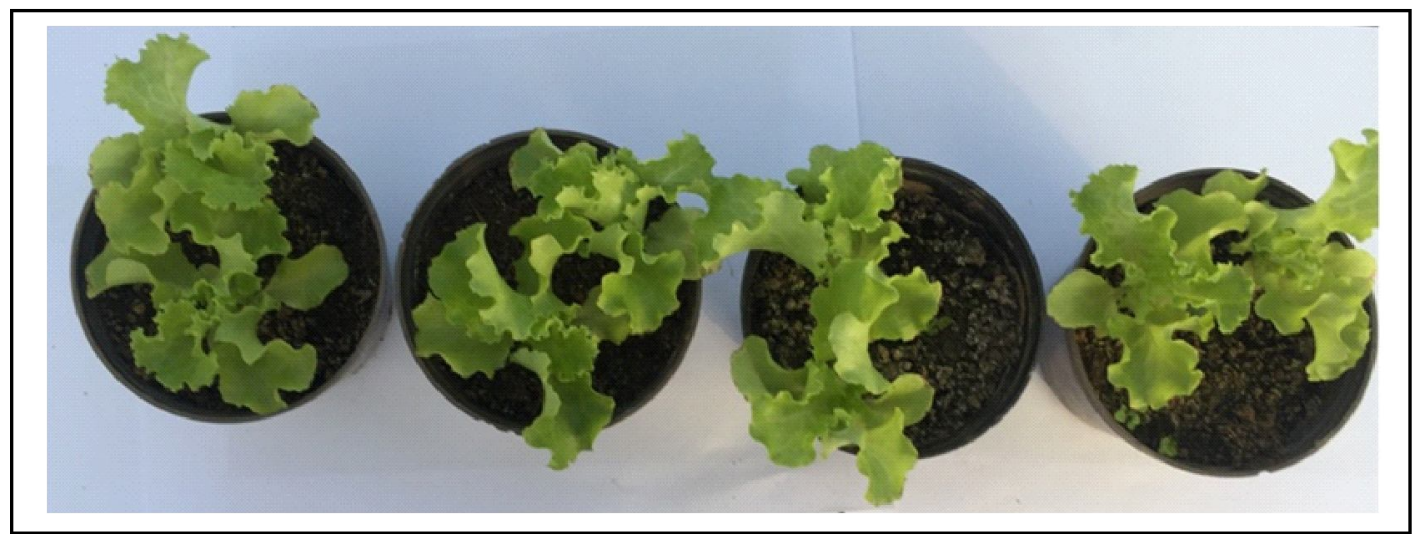

Figure 2: Lettuce growth under greenhouse conditions.

Table 1: Effect of biochar amendment $(1 \%, 2 \%, 3 \%)$ on leaf length, leaf number and leaf width of lettuce

\begin{tabular}{|l|c|c|c|}
\hline Treatments & Leaf length $(\mathbf{c m})$ & Leaf number & Leaf width $(\mathbf{c m})$ \\
\hline Control & $3.60 \pm 0.55$ & $5.20 \pm 0.45$ & $2.84 \pm 0.17$ \\
Biochar 1\% & $4.04 \pm 0.11$ & $5.80 \pm 0.45$ & $3.22 \pm 0.19$ \\
Biochar 2\% & $4.50 \pm 0.21^{*}$ & $6.20 \pm 0.45^{*}$ & $3.82 \pm 0.15^{*}$ \\
Biochar 3\% & $5.02 \pm 0.11^{*}$ & $6.40 \pm 0.55^{*}$ & $4.12 \pm 0.18^{* *}$ \\
\hline
\end{tabular}

Data are means of five replicates $(\mathrm{n}=5)$, asterisks indicate significant differences from the control at $p<0.05,<0.01$.

\subsection{Plant growth parameters of lettuce}

Biochar addition increased leaf length, leaf number and leaf width after 35 days, Table 1 and Figure 2. Both biochar 2\% and biochar 3\% treatments showed a positive effect on leaf length compared to the control and $1 \%$ treatment. Leaf length exhibited that biochar treatments of $2 \%$ and $3 \%$ enhanced leaf length by 25 and $39 \%$ over the control. Compared to the control, biochar treatments of $2 \%$ and $3 \%$ improved the leaf number by $19 \%$ and $23 \%$, respectively. The leaf width enhanced sharply with increasing levels of biochar additions of 2 and $3 \%$, which significantly improved by $34 \%$ and $45 \%$ compared to the control (Table 1). 
There were significant effects of biochar amendment of $1 \%$ on the root fresh weight and the root dry weight (Table 2). Compared to the control, the fresh root weight enhanced significantly by $35 \%$ and $43 \%$ for biochar treatments of $2 \%$ and $3 \%$, respectively. Accordingly, both biochar treatments significantly enhanced the root dry weight by $37 \%$ and $50 \%$. The biochar amendments of 2 and $3 \%$ also significantly increased the shoot fresh weight by $33 \%$ and $45 \%$ over the control and significantly increased the shoot dry weight by $24 \%$ and $38 \%$.

\subsection{Measurement of root system parameters}

The root system of lettuce are presented in Figure 3. There was no significant biochar effect of the $1 \%$ treatment on the total root length, the root surface area, the projected area and the root volume. However, biochar $1 \%$ treatment enhanced the root diameter by $22 \%$. Overall, biochar $2 \%$ and $3 \%$ treatments improved root morphological traits of lettuce at maximum compared to the control treatment. The root surface area improved significantly by $22 \%$ and $31 \%$ with increasing levels of biochar 2 and 3\% treatments, compared with the control. For instance, biochar $2 \%$ and $3 \%$ treatments significantly increased the projected area by $28 \%$ and $38 \%$ compared with the control, while the root diameter enhanced with increasing levels of biochar treatments by $55 \%$ and $67 \%$ and the root volume by $37 \%$ and 55\%. The total root length in the biochar 3\% treatment was 39\% higher than control, respectively (Table 3).

\subsection{Determination of plant physiological traits}

The influence of biochar levels on the total chlorophyll content of lettuce under greenhouse conditions is presented in Figure 2. The biochar $1 \%$ treatment slightly increased the chlorophyll content, however, the highest total chlorophyll content was with the biochar $3 \%$ treatment, which was $17 \%$ and $43 \%$ higher than for the biochar $1 \%$ and control treatments. In the treatment with $2 \%$ biochar application, the total chlorophyll content raises substantially by $33 \%$ compared to the control.

Control

Biochar 1\%

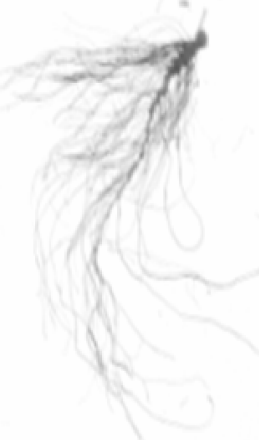

Biochar 2\%

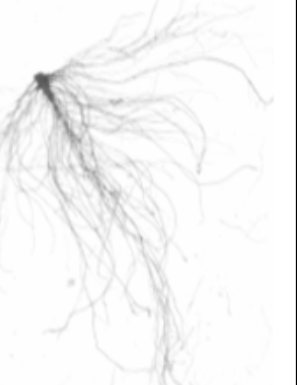

Biochar 3\%

Figure 3: Effects of biochar amendments $(1 \%, 2 \%, 3 \%)$ on the root system of lettuce.

Table 2: Effect of biochar amendment $(1 \%, 2 \%, 3 \%)$ on fresh root and shoot weight and on dry root and shoot weight of lettuce

\begin{tabular}{|l|c|c|c|c|}
\hline Treatments & Root fresh weight $(\mathbf{g})$ & Shoot fresh weight $(\mathrm{g})$ & Root dry weight $(\mathrm{g})$ & shoot dry weight $(\mathrm{g})$ \\
\hline Control & $2.81 \pm 0.01$ & $8.10 \pm 0.07$ & $0.16 \pm 0.01$ \\
Biochar 1\% & $3.34 \pm 0.01 *$ & $9.48 \pm 0.04$ & $0.19 \pm 0.01 *$ \\
Biochar 2\% & $3.80 \pm 0.02 *$ & $10.80 \pm 0.07 *$ & $0.22 \pm 0.01 *$ \\
Biochar 3\% & $4.02 \pm 0.03 * *$ & $11.72 \pm 0.04 * *$ & $0.24 \pm 0.01 * *$ \\
\hline
\end{tabular}

Data are means of five replicates $(n=5)$, asterisks indicate significant differences from the control at $p<0.05,<0.01$.

Table 3: Effect of biochar amendment $(1 \%, 2 \%, 3 \%)$ on root morphological traits of lettuce

\begin{tabular}{|c|c|c|c|c|c|}
\hline Treatments & $\begin{array}{c}\text { Total root length } \\
(\mathrm{cm})\end{array}$ & $\begin{array}{c}\text { Root surface area } \\
\left(\mathrm{cm}^{2}\right)\end{array}$ & $\begin{array}{l}\text { Projected area } \\
\left(\mathrm{cm}^{2}\right)\end{array}$ & $\begin{array}{c}\text { Root diameter } \\
(\mathbf{m m})\end{array}$ & $\begin{array}{c}\text { Root volume } \\
\left(\mathrm{cm}^{3}\right)\end{array}$ \\
\hline Control & $122.3 \pm 2.52$ & $9.50 \pm 0.10$ & $10.90 \pm 0.10$ & $0.18 \pm 0.01$ & $0.38 \pm 0.01$ \\
\hline Biochar 1\% & $133.0 \pm 3.53$ & $10.8 \pm 0.06$ & $12.5 \pm 0.20$ & $0.22 \pm 0.01 *$ & $0.44 \pm 0.01$ \\
\hline Biochar $2 \%$ & $143.0 \pm 6.56^{*}$ & $11.57 \pm 0.25^{*}$ & $13.97 \pm 0.15^{*}$ & $0.28 \pm 0.01 *$ & $0.52 \pm 0.02 *$ \\
\hline Biochar $3 \%$ & $170.6 \pm 1.97 *$ & $12.43 \pm 0.31 *$ & $15.10 \pm 0.26$ & $0.30 \pm 0.01 * *$ & $0.58 \pm 0.02 * *$ \\
\hline
\end{tabular}

Data are means of five replicates $(\mathrm{n}=5)$, asterisks indicate significant differences from the control at $p<0.05,<0.01$. 
Table 4: Effects of biochar amendment $(1 \%, 2 \%, 3 \%)$ on soil enzyme activities

\begin{tabular}{|c|c|c|c|c|}
\hline Treatments & $\begin{array}{c}\text { Acid phosphomo } \\
\text { no-esterase } \\
(\mu \mathrm{g} \text {-1 h-1) }\end{array}$ & $\begin{array}{c}\text { Alkaline phospho } \\
\text { monoesterase } \\
(\mu g \text { g-1 h-1 })\end{array}$ & $\begin{array}{c}\text { Fluorescein } \\
\text { diacetateactivity } \\
(\mu \mathrm{g} g-1 \mathrm{~h}-1)\end{array}$ & $\begin{array}{c}\text { Phenol oxidase } \\
\text { activity } \\
\text { (U.g-1 DW) }\end{array}$ \\
\hline Control & $900.2 \pm 26.6$ & $576.6 \pm 15.0$ & $35.2 \pm 0.65$ & $20.1 \pm 0.35$ \\
\hline Biochar $1 \%$ & $993.4 \pm 28.2$ & $645.5 \pm 13.2$ & $40.5 \pm 2.65$ & $27.6 \pm 1.10^{*}$ \\
\hline Biochar $2 \%$ & $1085.0 \pm 30.1 *$ & $656.4 \pm 12.7$ & $42.6 \pm 1.52 *$ & $31.3 \pm 1.65^{* *}$ \\
\hline Biochar $3 \%$ & $1178.8 \pm 37.3^{*}$ & $689.1 \pm 14.4 *$ & $44.8 \pm 3.69 *$ & $34.5 \pm 1.80 * *$ \\
\hline
\end{tabular}

Data are means of five replicates $(n=5)$, asterisks indicate significant differences from the control at $p<0.05,<0.01$.

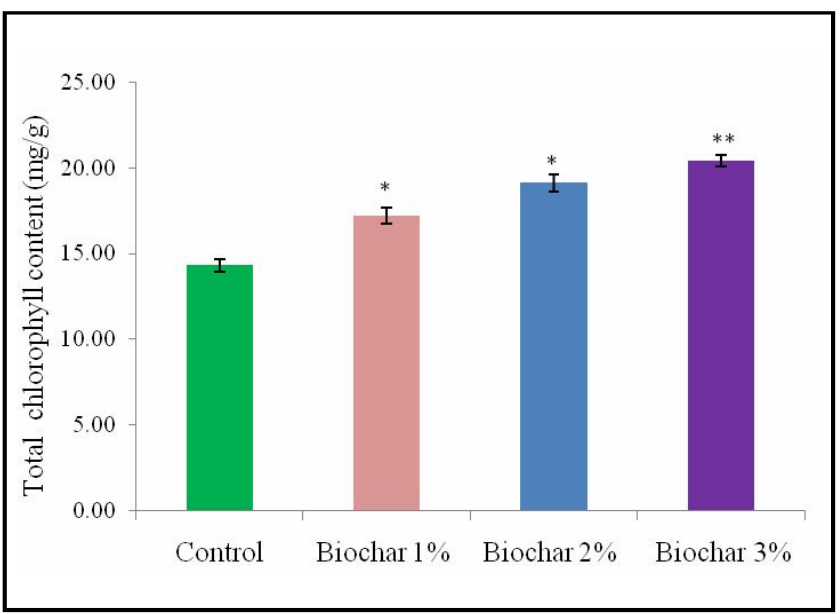

Figure 2: Effects of biochar amendments $(1 \%, 2 \%, 3 \%)$ on the total chlorophyll content of lettuce.

Data are means of five replicates $(n=5)$, asterisks indicate significant differences from the control at $p<0.05$.

The results in Figure 3 show that the carotenoid content of lettuce was substantially enhanced in treatments with $1 \%$ and $3 \%$ biochar. The biochar $1 \%$ and $2 \%$ treatments significantly increased the carotenoid content by $24 \%$ and $38 \%$, respectively. The highest carotenoid content was seen with biochar $3 \%$ treatment which was $17 \%$ and $51 \%$ higher than the biochar $1 \%$ and control treatments, respectively.

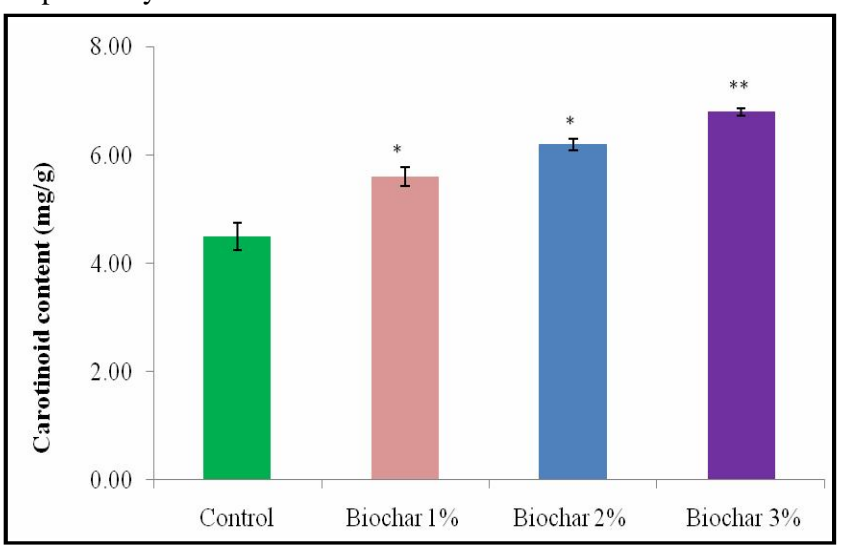

Figure 3: Effects of biochar amendments on the carotenoid content of lettuce.

Data are means of five replicates $(n=5)$, asterisks indicate significant differences from the control at $p<0.05,<0.01$.
Furthermore, biochar treatments increased the relative water content of lettuce. The treatments with $1 \%$ and $2 \%$ biochar slightly increased the relative water content in leaf tissues compared to the control, whereas the maximum relative water content was detected in the treatment with $3 \%$ biochar compared with control.

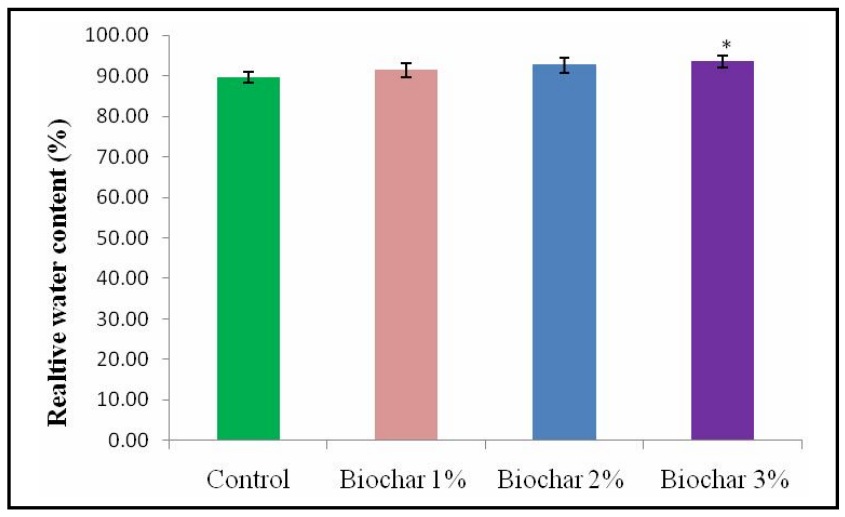

Figure 4: Effects of biochar amendments $(1,2 \%, 3 \%)$ on the relative water content of lettuce leaf tissues.

Data are means of five replicates $(n=5)$, asterisks indicate significant differences from the control at $p<0.05$.

\subsection{Estimation of soil enzyme activities}

The biochar application significantly improved soil enzymes activities, however, except for the fluorescein diacetate, and the acid and alkaline phosphomonoesterase activities, no significant differences were observed in the biochar $1 \%$ treatment (Table 4). The highest alkaline phosphomonoesterase activities were seen with the application of biochar 3\%, which was 19\% higher compared to the control treatment, respectively. The fluorescein diacetate hydrolase and phenol oxidase activities were also significantly increased with biochar $3 \%$ treatment by $27 \%$ and $72 \%$, compared to the control. The biochar $2 \%$ treatment significantly increased the acid phosphomonoesterase activity by $20 \%$ and the fluorescein diacetatehydrolase activity by $27 \%$ over the control. The phenol oxidase activity increased from $56 \%$ in biochar $2 \%$ treatment compared to the control.

\section{Discussion}

Previous reports indicated that the major effects of biochar application were based on enhancing seed germination, plant growth and finally yields of several crops such as chickpea (Hashem et al., 2019), soybean (Ma et al., 2019; Jabborova et al., 2020), spinach (Jabborova et al., 2021a) and okra (Jabborova et al., 2021d). Several plant growth parameters and root morphological traits of lettuce 
were significantly increased by biochar $2 \%$ and $3 \%$ treatments compared to control. Correspondingly, Carter et al. (2021) reported that rice-husk biochar application increased plant biomass, root biomass, plant height and number of leaves of cabbage (Brassica chinensis) and lettuce (Lactuca sativa) compared to the control. This finding confirms earlier studies by Nabavinia et al. (2015) that biochar application increased the root growth, root diameter, and yield of radish (Raphanus sativus). Liang et al. (2019) recorded a higher P.australis biomass in biochar treatment.This finding is also consistent with Usman et al. (2016), who observed a significant increase in tomato (Solanum lycopersicum) vegetative growth and yield that increased $14.0-43.3 \%$ by biochar. According to Gale and Thomas (2019), biochar generally increased plant growth and the concentration of micronutrients in Abutilon theophrasti and Trifolium repens. Correspondingly, the application rate of $10-15 \%$ sludge biochar on the green roof exerted the most significant effects on plant biomass by 54.0-54.2\% (Chen et al., 2018).

The addition of biochar enhanced root growth parameters and root morphological parameters such as the total root length, the root surface area, the projected area, the root diameter and the root volume compared to the control. Several researchers also found that biochar application enhanced root growth of different plants such as soybean (Glycine max L), ginger (Zingiber officinale) and also in case of basil (G3odowska et al., 2017; Ma et al., 2019; Jabborova et al., 2021b; Jabborova et al., 2021c).

In the present study, biochar 3\% treatment had a positive effect on lettuce physiological properties such as total chlorophyll and carotenoid contents as well as the relative water content of leaf tissues. Accordingly, numerous researchers found that biochar application increased plant physiological traits in different plants such as chickpea (Cicer arietinum), ginger (Zingiber officinale), and also for okra (Abelmoschus esculentus) (Hashemet al., 2019; Jabborova et al., 2021b; Zhang et al., 2020; Jabborova et al., 2021d). Similarly, biochar-amended a significant increase in the chlorophyll (41\%) of soybean plants when grown on a soil compared to the control (Qian et al., 2019). Younis et al. (2016) showed that biochar increases chlorophyll a by $29 \%$, chlorophyll b by $52 \%$, total chlorophyll by $33 \%$, and carotenoids by $5 \%$ in spinach (Spinacia oleracea). Similarly, results were reported by Zeeshan et al. (2020), who observed that biochar application significantly enhanced plant height, fresh and dry weight, chlorophyll $a, b$, total chlorophyll and carotene content.

Furthermore, our results indicated that biochar 3\% treatments significantly increased the activities of soil enzymes such as phenol oxidase, fluorescein diacetate hydrolase acid and alkaline phosphomonoesterase. These finding confirm earlier studies such as by Chen et al. (2013) who observed significant increase in alkaline phosphatase activity in soil amended with wheat straw biochar. Accordingly, enhanced soil enzyme activities was reported by Elzobair et al. (2016) after the addition of biochar. Earlier studies by Jabborova et al. (2020) and Jabborova et al. (2021b) who both observed the fluorescein diacetate hydrolase acid and alkaline phosphomonoe strase activities of the soil in biochar application. Biochar application significantly increased the phosphatase activity by $46 \%$ biochar application with the highest rate $12 \mathrm{t}$ ha (Oladele. 2019), biochar was $34 \%$. Similarly, Saeed et al. (2021) recorded the soil enzymatic activities had shown $38.5 \%$ increase in fluorescein diacetate hydrolysis and $55.6 \%$ increase in dehydrogenase activity in soil incubated with biochar in compared to control.

\section{Conclusion}

Both biochar treatments of $2 \%$ and biochar $3 \%$ significantly increased lettuce growth such as leaf length, leaf number and leaf width compared to the control. Therefore, biochar application at 3\% was rated to be sufficient for achieving the best root morphological traits such as total root length, root surface area, projected area and root volume. Moreover, biochar application at 3\% increased the total chlorophyll content and carotenoid content. Soil enzyme activities (fluorescein diacetate hydrolase, acid and alkaline phosphomonoesterase) were further increased by increasing rates of biochar application. Thus, results clearly indicated improved growth conditions of lettuce and soil enzyme activities after biochar amendment.

\section{Acknowledgments}

We thank colleagues at Leibniz Centre for Agricultural Landscape Research (ZALF), Müncheberg, Germany, for providing necessary support at laboratory and greenhouse facilities, namely; the Experimental Field Station and the Central Laboratory.

\section{Conflicts of interest}

The authors declare no conflicts of interest relevant to this article.

\section{References}

Adrados, A.; De Marco, I.; López-Urionabarrenechea, A.; Solar, J.; Caballero, B. and Gastelu, N. (2015). Biomass pyrolysis solids as reducing agents: comparison with commercial reducing agents. Materials, 9(3):1-18.

Akhtar, S.S.; Li, G.; Andersen, M.N. and Liu, F. (2014). Biochar enhances yield and quality of tomato under reduced irrigation. Agricultural Water Management,138:37-44.

Anderson, C.R.; Condron, L.M. and Clough, T.J. (2011).Biochar induced soil microbial community change: Implications for biogeochemical cycling of carbon, nitrogen and phosphorus. Pedobiologia, 54:309320.

Asai, H.; Samson, B.K.; Stephan, H.M.; Songyikhangsuthor, K.; Homma, K.; Kiyono, Y.; Inoue, Y.; Shiraiwa, T. and Horie., T. (2009). Biochar amendment techniques for upland rice production in Northern Laos, 1. Soil physical properties, leaf SPAD and grain yield. Field Crop Res., 111:81-84.

Barrs, H.D.;Weatherley, P.E. (1962).A re-examination of the relative turgidity technique for estimating water deficit in leaves. Aus. J. Biol. Sci., 15:413-428.

Carter, S.;Shackley, S.;Sohi, S.;Suy, T.B. and Haefele, S. (2013).The impact of biochar application on soil properties and plant growth of pot grown lettuce (Lactuca sativa) and cabbage (Brassica chinensis). Agronomy, 3:404-418.

Chen, J.; Liu, X.; Zheng, J.; Zhang, B.; Lu, H.; Chi, Z.; Pan, G.; Li, L.; Zheng, J.; Zhang, X. and Wang, J. (2013). Biochar soil amendment increased bacterial but decreased fungal gene abundance with shifts in community structure in a slightly acid rice paddy from Southwest China. Applied Soil Ecology, 71:33-44.

Chen, H.; Ma, J.; Wei, J.; Gong, X.; Yu, X.; Guo, H. and Zhao, Y. (2018). Biochar increases plant growth and alters microbial communities via regulating the moisture and temperature of green roof substrates. Science of The Total Environment, 635:333-342.

Chiesa, A.; Mayorga, I. and Leon, A. (2009). Quality of fresh cut lettuce (Lactuca sativa L.) as affected by lettuce genotype, nitrogen fertilisation and crop season. Adv. Hort. Sci., 23:143-149.

Chrysargyris, A.; Prasad, M.; Kavanagh, A. and Tzortzakis, N. (2019). Biochar type and ratio as a peat additive/partial peat replacement in growing media for cabbage seedling production. Agronomy, 9:693. 
Elzobair, K.A.; Stromberger, M.E. and Ippolito, J.A. (2016). Stabilizing effect of biochar on soil extracellular enzymes after a denaturing stress. Chemosphere, 142:114-119.

Floch, C.; Gutiérrez, E.A. and Criquetm S. (2007). ABTS assay of phenol oxidase activity in soil. Journal of Microbiological Methods, 71:319-324.

Gale, N.V. and Thomas, S.C. (2019). Dose-dependence of growth and ecophysiological responses of plants to biochar. Science of the Total Environment, 658:1344-1354.

G33odowska, M.;Schwinghamer, T.; Husk, B. and Smith, D. (2017).Biochar based inoculants improve soybean growth and nodulation. Agric. Sci.; 8: $1048-1064$

Green, V.S.; Stott, D.E. and Diack, M. (2006). Assay for fluorescein diacetate hydrolytic activity: Optimization for soil samples. Soil Biol. Biochem., 38:693-701, doi:10.1016/j.soilbio.2005.06.020.

Hale, S.E.; Alling, V.; Martinsen, V.; Mulder, J.; Breedveld, G.D. and Cornelissen. G (2013). The sorption and desorption of phosphate-P, ammonium-N and nitrate- $\mathrm{N}$ in cacao shell and corn cob biochars. Chemosphere, 91:1612-1619.

Hashem, A.; Kumar, A.; Al-Dbass, A.M.;Alqarawi, A.A.; Al-Arjani, A.B.;Singh, G;Farooq, M. and Abd Allah, E.F. (2019). Arbuscular mycorrhizal fungi and biochar improves drought tolerance in chickpea. Saudi Journal of Biological Sciences, 26:614-624.

Hiscox, J.D. and Israelstam, G.F. (1979).A method for the extraction of chlorophyll from leaf tissue without maceration. Can. J. Bot., 57:1332-1334.

Jabborova, D.; Wirth, S.; Kannepalli, A.; Narimanov, A.; Desouky, S.; Davranov, K.; Sayyed R.Z, El Enshasy, H.; Malek, R.A.; Syed, A. and Bahkali, A.H. (2020). Co-inoculation of rhizobacteria and biochar application improves growth and nutrients in soybean and enriches soil nutrients and enzymes. Agronomy, 10:1142. doi:10.3390/agronomy 10081142.

Jabborova, D.; Annapurna, K.; Paul, S.; Kumar, S.; Saad, H. A.; Desouky, S. and Elkelish, A. (2021a). Beneficial features of biochar and arbuscular mycorrhiza for improving spinach plant growth root morphological traits, physiological properties, and soil enzymatic activities. Journal of Fungi, 7:571.

Jabborova, D.; Wirth, S.; Halwani, M.; Ibrahim, M. F.; Azab, I. H. E.; El-Mogy, M. M and Elkelish, A. (2021b). Growth response of ginger (Zingiber officinale), its physiological properties and soil enzyme activities after biochar application under greenhouse conditions. Horticulturae, 7:250.

Jabborova, D.; Ma, H.; Bellingrath-Kimura, S. D. and Wirth, S. (2021c). Impacts of biochar on basil (Ocimum basilicum) growth, root morphological traits, plant biochemical and physiological properties and soil enzymatic activities. Scientia Horticulturae, 290:110518.

Jabborova, D.; Annapurna, K.; Al-Sadi, A. M.; Alharbi, S. A.; Datta, R. and Zuan A.T.K.(2021d). Biochar and Arbuscular mycorrhizal fungi mediated enhanced drought tolerance in okra (Abelmoschus esculentus) plant growth, root morphological traits and physiological properties. Saudi Journal of Biological Sciences, 28:5490-5499.

Jaiswal, A.K. (2020). Nutritional composition and antioxidant properties of fruits and vegetables. Academic Press, pp:143-157.

Kookana, R.S, Zwieten, V.L.; Krull.E. and Singh, B. (2011). Biochar application to soil: Agronomic and environmental benefits and unintended consequences. Adv. Agron., 112:103-143.

Labeda, A.; Ryder, E. J.; Grube, R.; Dolezalova, I. and Kristkova, E. (2007). Lettuce (Asteraceae; Lactuca spp.) In: Singh, R.J. (ed.). Genetic resources, chromosome engineering, and crop improvement.Vegetable Crops. Boca Raton, CRC Press, Tailor and Francis Group, pp:377-472.

Laird, D.A.; Fleming, P.; Davis, D.D.; Horton, R.; Wang, B. and Karlen, D.L. (2010) Impact of biochar amendments on the quality of a typical Midwestern agricultural soil.Geoderma, 158:443-449.
Lehmann, J.; Rillig, M.C.; Thies, J.; Masiello, C.A.; Hockaday, W.C. and Crowley, D. (2011). Biochar effects on soil biota: A review. Soil Biol. Biochem., 43:1812-1836. https://doi.org/10.1016/j.soilbio.2011.04.022.

Liang, J.F.; An, J.; Gao, J.Q.; Thang, X.Y.; Song, M.H. and Yu, F.H. (2019). Interactive effects of biochar and AMF on plant growth and greenhouse gas emissions from wetland microcosms. Geoderma, 346:11-17.

Ma, H.; Egamberdieva, D.; Wirth, S. and Bellingrath-Kimura, S.D. (2019). Effect of biochar and irrigation on soybean-rhizobium symbiotic performance and soil enzymatic activity in field rhizosphere. Agronomy, 9:626.

Martinsen, V.; Alling, V.; Nurida, N.L.; Mulder, J.; Hale, S.E.; Ritz, C.; Rutherford, D.W.; Heikens, A.; Breedveld, G.D. and Cornelissen, G. (2015). pH effects of the addition of three biochars to acidic Indonesian mineral soils. Soil Sci. Plant Nutr.; 61:821-834.

Mulabagal, V.;Ngouajio, M.; Nair, A.; Zhang, Y.;Gottumukkala, A.L. and Nair, M.G. (2010). In vitro evaluation of red and green lettuce (Lactuca sativa) for functional food properties. Food Chem.; 118:300-306.

Nabavinia, F.;Emami, H.;Astaraee, A. and Lakzian, A. (2015). Effect of tannery wastes and biochar on soil chemical and physicochemical properties and growth traits of radish. Int. Agrophysics, 29:333-339.

Nahhas, N.E.; Abdelaal, K.A.; AlKahtani, M.D.; Al Husnain, L.; AlGwaiz, H.I.; Hafez, Y.M.; Attia, K.A.; El-Esawi, M.A.; Ibrahim, M.F. and Elkelish, A. (2021). Biochar and jasmonic acid application attenuate antioxidative systems and improves growth, physiology, nutrient uptake and productivity of faba bean (Vicia faba L.) irrigated with saline water. Plant Physiology and Biochemistry, 166:807-817.

Oladele, S.O. (2019). Effect of biochar amendment on soil enzymatic activities, carboxylate secretions and upland rice performance in a sandy clay loam Alfisol of Southwest Nigeria. Scientific African, 4: e00107.https://doi.org/10.1016/j.sciaf.2019.e00107.

Qian, Z.H.U.; Kong, L.;Shan, Y.; Yao, X.; Zhang, H.;Xie, F. and Xue, A.O. (2019). Effect of biochar on grain yield and leaf photosynthetic physiology of soybean cultivars with different phosphorus efficiencies. J. Integr. Agric.; 18:2242-2254

Saeed, M.; Ilyas, N.; Jayachandran, K.; Gaffar, S.; Arshad, M.; Ahmad, M.S.; Bibi, F.; Jeddi, K. and Hessini, K. (2021).Biostimulation potential of biochar for remediating the crude oil contaminated soil and plant growth. Saudi Journal of Biological Sciences, 28:2667-2676.

Sarma, B.;Borkotoki, B.;Narzari, R.;Kataki, R. and Gogoi, N. (2017).Organic amendments: Effect on carbon mineralization and crop productivity in acidic soil. Journal of Cleaner Production, 152:157-166.

Scis ${ }^{3}$ owska, M.; Wºdarczyk, R.; Koby ${ }^{3}$ ecki, R. and Bis, Z. (2015).Biochar to improve the quality and productivity of soils. Journal of Ecological Engineering, 3:31-35. doi:10.12911/22998993/2802.

Speratti,A.B.; Johnson, M.S.; Sousa, H.M.; Dalmagro, H.J. and Couto, E.G (2018). Biochars from local agricultural waste residues contribute to soil quality and plant growth in a Cerrado region (Brazil) Arenosol. GCB Bioenergy, 10:272-286.

Tabatabi, M.A. and Bremner, J.M. (1969). Use of p-nitrophenol phosphate for the assay of soil phosphatase activity. Soil Biol. Biochem., 1:301-307. 10.1186/1756-0500-7-221.

Tabatabai, M.A. (1994). Soil enzymes. In: Weaver, R.W.; Angle, J.S.; Bottomley, P.S. (Eds.), methods of soil analysis: Microbiological and biochemical properties. Part 2 Book Series 5, Soil Science Society of America, Madison, WI: 775-833. 
Usman, A.R.A.; Al Wabel, M.I.; Abdulaziz, A.H.; Mahmoud, W.A.; El Naggar, A.H.; Ahmad, M.;Abdulelah, A.F. and Abdulrasoul, A.O. (2016). Conocarpus biochar induces changes in soil nutrient availability and tomato growth under saline irrigation. Pedosphere, 26:27-38.

Vaccari, F.P.; Maienza, A.; Miglietta, F.; Baronti, S.; Di Lonardo, S.; Giagnoni, L. and Genesio, L. (2015). Biochar stimulates plant growth but not fruit yield of processing tomato in a fertile soil. Agriculture, Ecosystems and Environment, 207:163-170.

Vaughn, S. F.; Byars, J. A.; Jackson, M. A.; Peterson, S. C. and Eller, F. J. (2021) Tomato seed germination and transplant growth in a commercial potting substrate amended with nutrient-preconditioned Eastern red cedar (Juniperu svirginiana L.) wood biochar. Scientia Horticulturae, 280:109947.

Xylia, P.;Chrysargyris, A. and Tzortzakis, N. (2021). The combined and single effect of Marjoram essential oil, ascorbic acid, and chitosan on fresh-cut lettuce preservation. Foods, 10:575.
Yoo, J.H.; Luyima, D.; Lee, J.H.; Park, S.Y.; Yang, J.W.; An, J.Y.; Yun, Y.U. and Oh, T.K. (2021). Effects of brewer's spent grain biochar on the growth and quality of leaf lettuce (Lactuca sativa L. var. crispa.). Applied Biological Chemistry, 64:1-10.

Younis, U.; Malik, S.A.;Rizwan, M.;Qayyum, M.F.; Ok, Y.S.;Shah, M.H.R.;Rehman, R.A. and Ahmad, N. (2016). Biochar enhances the cadmium tolerance in spinach (Spinacia oleracea) through modification of Cd uptake and physiological and biochemical attributes. Environ. Sci. Pollut. Res., 23:21385-21394.

Zeeshan, M.; Ahmad, W.; Hussain, F.; Ahamd,W.; Numan, M.; Shah,M. and Ahmad, I. (2020). Phytostabalization of the heavy metals in the soil with biochar applications, the impact on chlorophyll, carotene, soil fertility and tomato crop yield. Journal of Cleaner Production, 255: 120318

Zhang, Z; Dong, X.; Wang, S. and Pu, X. (2020). Benefits of organic manure combined with biochar amendments to cotton root growth and yield under continuous cropping systems in Xinjiang, China. Sci. Rep., 10:1-10.

Dilfuza Jabborova, Dilbar Kadirova, Abdujalil Narimanov and Stephan Wirth (2021). Beneficial effects of biochar 